\title{
Three-dimensional beam pattern of regular sperm whale clicks confirms bent-horn hypothesis
}

\author{
Walter M. X. Zimmer \\ NATO Undersea Research Centre, V.le San Bartolomeo 400, 19138 La Spezia, Italy
}

Peter L. Tyack, Mark P. Johnson, and Peter T. Madsen

Woods Hole Oceanographic Institution, Woods Hole, Massachusetts 02543

(Received June 30, 2004; revised September 30, 2004; accepted October 11, 2004)

\begin{abstract}
The three-dimensional beam pattern of a sperm whale (Physeter macrocephalus) tagged in the Ligurian Sea was derived using data on regular clicks from the tag and from hydrophones towed behind a ship circling the tagged whale. The tag defined the orientation of the whale, while sightings and beamformer data were used to locate the whale with respect to the ship. The existence of a narrow, forward-directed $\mathrm{P} 1$ beam with source levels exceeding $210 \mathrm{~dB}_{\text {peak }} r e: 1 \mu \mathrm{Pa}$ at $1 \mathrm{~m}$ is confirmed. A modeled forward-beam pattern, that matches clicks $>20^{\circ}$ off-axis, predicts a directivity index of $26.7 \mathrm{~dB}$ and source levels of up to $229 \mathrm{~dB}_{\text {peak }}$ re: $1 \mu \mathrm{Pa}$ at $1 \mathrm{~m}$. A broader backward-directed beam is produced by the $\mathrm{P} 0$ pulse with source levels near $200 \mathrm{~dB}_{\text {peak }} r e: 1 \mu \mathrm{Pa}$ at $1 \mathrm{~m}$ and a directivity index of $7.4 \mathrm{~dB}$. A low-frequency component with source levels near $190 \mathrm{~dB}_{\text {peak }} r e: 1 \mu \mathrm{Pa}$ at $1 \mathrm{~m}$ is generated at the onset of the P0 pulse by air resonance. The results support the bent-horn model of sound production in sperm whales. While the sperm whale nose appears primarily adapted to produce an intense forward-directed sonar signal, less-directional click components convey information to conspecifics, and give rise to echoes from the seafloor and the surface, which may be useful for orientation during dives. (c) 2005 Acoustical Society of America. [DOI: $10.1121 / 1.1828501]$
\end{abstract}

PACS numbers: 43.80.Ka, 43.80.Ev, 43.30.Sf [WWA] Pages: 1473-1485

\section{INTRODUCTION}

The vocal repertoire of sperm whales is generally reported to be limited to click sounds. Individual sperm whales can produce a variety of kinds of clicks, which are thought to function for several different echolocation and communicative functions. When diving, sperm whales produce long series of clicks with regular interclick intervals (ICI) of 0.5-2 s (called "usual clicks" by Whitehead and Weilgart, 1991). The purpose of these regular clicks was long disputed. Most biologists assumed by analogy with the better-studied biosonar of bats and dolphins that regular clicks are used for echolocation (Backus and Schevill, 1966; Gordon, 1987). However, several bio-acousticians have argued that the observed mean source level (160-180 dB re: $1 \mu \mathrm{Pa}$ at $1 \mathrm{~m})$ and the lack of significant directionality were not compatible with successful echolocation of prey (Watkins, 1980; Fristrup and Harbison, 2002). Recent measurements suggest that regular clicks are in fact highly directional, with source levels of up to $235 \mathrm{~dB}_{\text {rms }}$ re: $1 \mu \mathrm{Pa}$ at $1 \mathrm{~m}$ on the axis of the sound beam (Møhl et al., 2003). Tyack (1997) showed echoes of regular clicks from the seafloor, and Jaquet et al. (2001) and Gordon and Tyack (2002) demonstrated that the first clicks at the start of the descent of a dive correlated with the round-trip travel time to the bottom in some locations. These data suggest that sperm whales echolocate at least on the seafloor.

Diving sperm whales also make bursts of clicks with higher repetition rates, called "creaks" (Gordon, 1987; Mullins et al., 1988; Madsen et al., 2002). By analogy with the terminal buzz produced when some bat species close on aerial prey (Griffin, 1958), most authors have suggested that usual clicks produced at the bottom of foraging dives may represent a search phase of echolocation, and that sperm whales produce creaks, or terminal buzzes, as they close on prey.

Sperm whales also make clicks assumed to be used for social communication. Weilgart and Whitehead (1988) describe distinctive intense reverberant clicks with long ICI typically of 5-7 s. These were only recorded in the presence of mature males and are thought to advertise the maturity and competitive ability of the male. Stereotyped repetitive series of clicks called "codas" (Watkins and Schevill, 1977) are recorded from many different groups of sperm whales, especially when whales are socializing near the surface (Gordon, 1987; Whitehead and Weilgart, 1991). These coda vocalizations are thought to function for social communication within these groups (Weilgart and Whitehead, 1993; Moore et al., 1993; Rendell and Whitehead, 2003).

Backus and Schevill (1966) observed that sperm whale clicks last in excess of $10 \mathrm{~ms}$ and are composed of a series of pulses of short duration $(0.1-2 \mathrm{~ms})$. They showed further that the relative amplitude and timing of the pulses within the clicks obey no consistent rule among whales. However, the relative amplitudes and timing show an apparent reproducibility from click to click from individual whales at least on a short time scale; Backus and Schevill (1966) considered this as signature for the individuals. Norris and Harvey (1972) proposed that sperm whale clicks are generated by the so-called phonic lips (also known as the museau de singe, or monkey lips) and that the dominating first pulse is directly transmitted into the water ahead of the whale, while the re- 


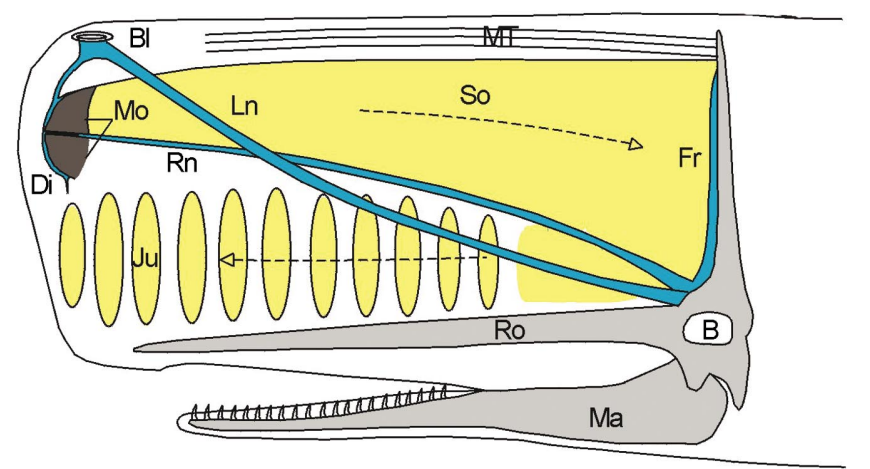

$1 \mathrm{~m}$

FIG. 1. Diagram of bent-horn model of sound production in sperm whales (modified from Fig. 1 of Madsen et al. 2002). B, brain; Bl, blow hole; Di, distal air sac; Fr, frontal air sac; Ju, junk; Ln, left naris; Ma, mandible; Mo, monkey lips/museau de singe; MT muscle/tendon layer; Rn, right naris; Ro rostrum; So, spermaceti organ.

maining pulses represent reverberations of the backwardly directed portion of the original pulse that are reflected between two reflecting air sacs that bound the ends of the spermaceti organ. Concerning the way the reverberated pulses leave the spermaceti organ, Norris and Harvey (1972) were inconclusive and proposed two possibilities for the exact exit site, the upper phonic lip, at the anterior termination of the spermaceti organ, or alternatively the well-developed mesorostral cartilage of the rostrum (Norris and Harvey, 1972).

The Norris and Harvey (1972) sound generation model for sperm whales has been modified by Møhl (2001), who proposed in his "bent-horn" model that some of the acoustic energy generated by the phonic lips (labeled "Mo" in Fig. 1) escapes directly into the water, generating a P0 pulse. The majority of acoustic energy propagates back through the spermaceti organ ("So" in Fig. 1) to the frontal air sac (Fr) in front of the skull, where it is reflected downward and forward into the junk (Ju), from which it propagates into the seawater as a forward-directed P1 pulse. The remaining sound energy is reflected from the frontal sac back into the spermaceti organ where it returns to the distal sac. Most of this energy is again reflected backwards to repeat the path of the original path, and so on for P2, P3, etc pulses (Møhl, 2001). Acoustic data from a sperm whale neonate in rehabilitation confirmed that sperm whale clicks are produced at phonic lips in the anterior end of the spermaceti organ, and that sound produced there reverberates in the spermaceti organ and is transmitted to the seawater via the junk complex (Madsen et al., 2003; Møhl et al., 2003).

Møhl et al. $(2000,2003)$ used a dispersed array of hydrophones to test the hypothesis of an intense, directional P1 pulse predicted by the bent horn model. By selecting a few clicks from entire seasons of recording, they showed that some sperm whale clicks have centroid frequencies of about $15 \mathrm{kHz}$, high directionality of over $27 \mathrm{~dB}$, and source levels of up to $235 \mathrm{~dB}_{\text {rms }}$ re: $1 \mu \mathrm{Pa}$ at $1 \mathrm{~m}$. While they could not measure the orientation of the clicking whale directly, Møhl et al. $(2000,2003)$ assumed that if they detected a strong click with a dominant single pulse, this would represent an on-axis recording in the beam of the P1 pulse. They argue that this high source level and the narrow sound beam represent adaptations for long-range echolocation on mesopelagic prey with low target strength (Møhl et al., 2003; Madsen et al., 2002).

By contrast, Watkins (1980) analyzed data from dozens of cruises and reported that sperm whale clicks have variable spectra and no apparent propagation directionality. Watkins (1980) observed that the spectral component of sperm whale clicks extended over $30 \mathrm{kHz}$ when the whales were within 20 $\mathrm{m}$. At about $2 \mathrm{~km}$ most of the audible energy was below 5 to $6 \mathrm{kHz}$ with apparent emphases at 2 to $4 \mathrm{kHz}$. Watkins and Daher (2004) presented the underwater recordings of fast click sequences $(2.3 / \mathrm{s}$ to $8.8 / \mathrm{s})$ of a small whale near the surface during head-out episodes when the whale exposed the lower jaw as far as the jaw hinge. They state that they did not observe directional clicks as reported by Møhl et al. (2000).

These two views on the acoustic properties of clicks led to strikingly different interpretations as to their function. Watkins (1980) concluded that sperm whale regular clicks appeared to be used mostly for communication to coordinate movements of whales as they dive and disperse. While recognizing that most other researchers assumed an echolocation functionality for sperm whale clicks, Watkins (1980) pointed out that his observations of sperm whale sounds did not match the characteristics expected for an echolocation signal, especially when compared with the click characteristics from echolocating dolphins: sperm whale clicks do not appear to be highly directional; the click repetition rate is generally very regular and in particular does not vary with the changing distance to approaching targets; sperm whales can be silent for long periods, especially when they are alone; sperm whale clicks can be heard over such long distances that sound signal distortion becomes a limiting factor; individual clicks are longer and more complex than the echolocation signals of other odontocetes, most of which are thought to approximate an impulse. In summary, Watkins concluded that sperm whale clicks do not have acoustic features expected for echolocation, but rather seem to fit a context of communication (Watkins, 1980). Other researchers such as Fristrup and Harbison (2002) have also been skeptical of the idea that regular clicks can be successfully used for echolocation due to the low target strength of squid.

Here, we present data to suggest how such two very different views on sperm whale clicks may have been reached. We demonstrate that the P1 pulse does form a highpowered, forward-directed beam with properties consistent with the conclusions of Møhl et al. (2000, 2003). The initial pulse generates a P0 pulse and associated low-frequency components that are relatively omnidirectional, which may explain the conclusions reached by Watkins, who apparently never recorded the narrow, forward-directed P1 pulse on axis. Our data indicate that the P0 pulse contains $<10 \%$ of the energy of the P1 pulse, but this is still intense enough to be detectable over long distances and even to generate echoes from the seafloor and the surface. The P0 pulse has a backwards directionality that is a necessary and heretofore unpredicted consequence of the bent-horn model. We show that regular clicks of sperm whales have temporally and 
spectrally separated acoustic components by which the animal simultaneously produces a narrow, high-frequency sonar beam to search for prey, and less directional components that may be used for communication and perhaps orientation. A similar dual function of biosonar signals has been proposed for the high- and low-frequency components of harbor porpoise clicks (Møhl and Andersen, 1973).

\section{MATERIALS AND METHODS}

Our paper is based on data recorded in the Ligurian Sea in 2001 during Sirena-01, a field trial organized by the NATO Undersea Research Center (NURC) as part of its Marine Mammal Acoustic Risk Mitigation program. The data collection during Sirena trials was based on multiple components: visual observation of animals at the surface, passive sonar detection and tracking while animals were diving, and tagging of animals with a compact acoustic data recorder (Johnson and Tyack, 2003) developed by the authors at the Woods Hole Oceanographic Institution (WHOI).

The procedure for tagging sperm whales was based on the following scheme: During the night and early morning, visual observers and operators of a passive sonar tried to locate and to approach sperm whales for tagging. Once a sperm whale was tracked acoustically and visually, a small workboat was deployed from NRV ALLIANCE to attach the tag to the animal. Any potential responses to tagging were monitored visually and acoustically from NRV ALLIANCE as well as from the small vessel. After tagging, the whale could be followed visually when close to the ship, acoustically when it was clicking, and using a radio direction finder to track a VHF radio transmitter on the tag when the whale surfaced.

\section{A. Visual observation}

A visual watch was established during daylight hours on the flying bridge of NRV ALLIANCE, which provided a stable platform for visual observation at a height of $16 \mathrm{~m}$ over the water. Big-eye binoculars enabled observation up to $10 \mathrm{~km}$. Once a whale was located either visually or acoustically, it was selected as the "focal follow" animal and its detailed behavior (blow rate, swim speed, etc.) was recorded to establish behavioral patterns.

\section{B. Passive sonar}

A major asset available during Sirena trials was the passive sonar system on the NRV ALLIANCE. This passive sonar was developed at NURC and consisted of a horizontal line array that was towed at about 80-m depth, just below any substantial thermocline, a real-time digital beamformer, and sonar display system. It was deployed almost continuously, enabling a 24-h listening operation during most weather conditions up to sea state 7. Passive sonar technology was applied to detect and to track vocalizing animals when they were submerged and therefore not visible. Sperm whales are known to emit intense clicks at regular intervals while they are diving, and consequently are ideal for tracking by passive sonar.
Underwater signals were received by a towed line array of 128 hydrophones with the system saturation set to $140 \mathrm{~dB}_{\text {peak }} r e: 1 \mu \mathrm{Pa}$. The hydrophone separation was $9 \mathrm{~cm}$ and the sampling frequency was $31.25 \mathrm{kHz}$, allowing a maximum bandwidth of about $15 \mathrm{kHz}$. The acquired acoustic data were archived on a 240-Mbit/s digital tape recorder, together with relevant nonacoustic data such as array depth and ship's position, heading, and speed. The received array data were transformed to angular space using a digital time-delay beamformer (Zimmer et al., 2003). The beamformed data were used to find potential animals for tagging during the night and to track them during their deep dives. A close handshaking with the visual team made sure that focal animals were not lost. The continuous acoustic watch brought NRV ALLIANCE also in good positions to sight surfacing animals.

While the beamformer was useful for tracking the focal animal, a broadband analysis is more properly done with the data from individual hydrophones. For the subsequent analyses, data from two hydrophones (10.62 m apart) and relevant nonacoustic data (array depth, ship's position, GPS time stamp) were extracted from the hydrophone recordings.

\section{Tagging}

The passive sonar was able to track the gross movements of the whale, but not to record the detailed orientation or short-term movements of the animal between clicks. A digital tag (DTAG), developed by the authors at WHOI, was therefore used to record sound and high-resolution movement patterns directly from the whale (Johnson and Tyack, 2003). Key features of the DTAG were 16-bit analog-todigital conversion at a hydrophone sampling rate of $32 \mathrm{kHz}$ and clipping level set to $153 \mathrm{~dB}_{\text {peak }} r e: 1 \mu \mathrm{Pa}$, further pressure sensor, 3-axis accelerometer, and 3-axis magnetometer, all sampled at $50 \mathrm{~Hz}$.

The tagging team approached the focal animal in a small boat at low speed. The tag was deployed by means of a $12-\mathrm{m}$ carbon-fiber pole, mounted in a bow-mounted cantilever and attached to the whale with suction cups. After a preprogramed release time, the tag floated to the surface and was then tracked by taking bearings to a built-in VHF radio transmitter. The data acquired by the sensors of the tag were recorded on 3-GB flash memory, downloaded after recovery, and stored on CD-R for archiving and processing.

The recordings of the DTAG on the whale are in general not in synchrony with the passive sonar recordings on board NRV ALlianCE. Synchronization is therefore a critical step in the data processing and will be addressed in Sec. III C 3 .

\section{DATA PROCESSING}

The main goals of the data analysis were to obtain temporal, spectral, and level characteristics of sperm whale clicks as a function of spatial orientation of the whale with respect to a far-field sensor. Two data processing tasks had to be undertaken to achieve these analysis goals: to determine the motion and orientation of the sperm whale and to extract the temporal, spectral, and level characteristics of each click 
from the acoustic recordings. The data available were visual observations, tag and passive sonar recordings.

\section{A. Visual}

When the focal whale was at the surface, the visual team observed it continuously from the flying bridge of NRV AlliANCE. Range and bearing were logged into a computerized logging system for each behavioral event, such as blow, fluke-up, breach, etc. To estimate the target range, the reticule scale of the Big-eyes was used to measure the vertical angle of the focal animal below the horizon (Kinzey and Gerrodette, 2001). To estimate the bearing of the animal, the Big-eyes was fitted with a bearing encoder, which gave the bearing relative to the bow of the ship. The readout of the ship's gyroscope was then used to convert the relative bearing to absolute bearing of the focal animal. The availability of the ship's gyro eliminated the requirement for a magnetic compass that was considered problematic in proximity to metal structures on the flying bridge.

\section{B. Tag data}

The tag was the primary data source for the time at which the whale emitted each click, and for animal depth and orientation.

\section{Click detection and classification}

The times at which the clicks were emitted by the tagged animal were extracted from the acoustic recordings using an automatic click detector. The click detector was based on the Page test, a sequential probability ratio test that takes as input the time series of the received sound and determines beginning and end of transients (detections) by means of the following algorithm (Page, 1954; Wald, 1947; Abraham, 2000):

Given the instantaneous signal magnitude $x_{n}$, calculate a test variable $V_{n}$ and make the decision for detection of a transient or signal according to

$$
\begin{aligned}
V_{n}= & V_{n-1}+\left(\frac{x_{n}^{2}}{N_{n}}-b\right) \\
& \times \begin{cases}>V_{1} & \text { decide detection and set } V_{n}=V_{1}, \\
<V_{0} & \text { decide noise and set } \quad V_{n}=V_{0},\end{cases}
\end{aligned}
$$

with $N_{n}=$ noise estimate; $b=$ bias for test variable; $V_{0}$ $=$ threshold for decision of noise; and $V_{1}=$ threshold for decision of detection.

To obtain the signal magnitude, the real-valued data were first Hilbert transformed to a complex-valued (analytic) representation.

For each sample the detector algorithm could output one of three states, decision for signal, decision for noise, or decision deferred. In the last case the test variable $V_{n}$ was augmented by a new measurement. We defined the duration of the signal by the time between the last noise decision and the time of the last signal decision. It can be shown that in theory, bias and thresholds may be related to the detection probability and probability of false alarm (Wald, 1947). However, for this analysis the values were determined em- pirically to give good detection performance: $b=4, V_{0}=1$, and $V_{1}=10^{3}$. The noise was estimated by exponential weighting $N_{n}=(1-\alpha) N_{n-1}+\alpha x_{n}^{2}(\alpha=1 / 32)$ while noise was detected, or kept constant during signal detection. To avoid unrealistic long detections the maximum duration of any single detection was limited to $0.1 \mathrm{~s}$, a value that is about 10 times a complete sperm whale click.

After signal (transient) detection, classification was based on the temporal characteristics of regular clicks, such as the slowly varying time interval between clicks and slowly varying peak levels of clicks. Initially, only two detection categories were defined: sperm whale clicks and echoes reflected from the surface. The signal detection was classified as a sperm whale click when the interval to the next sperm whale click was similar to the interval to the previous sperm whale click with compatible signal levels and click durations. A surface-reflected echo was expected to occur shortly after a sperm whale click with a delay that corresponded to twice the whale depth.

\section{Animal depth and orientation}

The animal depth is measured by a calibrated pressure sensor in the DTAG. A key innovation of the DTAG is its ability to measure the orientation of the tagged animal as a function of time. Orientation is deduced from the 3-axis accelerometer and magnetometer signals and is expressed in terms of the Euler angles, pitch, roll, and heading, with reference to the fixed (earth) frame. As the tag may be placed anywhere on the back of a whale, the tag axes do not generally coincide with the whale axes. There are thus three frames involved: the tag frame, the whale frame, and the earth frame. To determine the orientation of the whale, the angles of rotation (pitch, roll, and heading) relating the whale frame to the earth frame were determined from the DTAG's accelerometer and magnetometer. (Johnson and Tyack, 2003; Zimmer et al., 2003).

\section{Animal tracking}

In general, for known animal speed $v(t)$, pitch and heading the animal track may be estimated by

$$
\left(\begin{array}{l}
p_{x}(t) \\
p_{y}(t) \\
p_{z}(t)
\end{array}\right)=\left(\begin{array}{l}
p_{x}\left(t_{0}\right) \\
p_{y}\left(t_{0}\right) \\
p_{z}\left(t_{0}\right)
\end{array}\right)+\int_{t_{0}}^{t} v(\tau)\left(\begin{array}{c}
\cos \beta(\tau) \sin \gamma(\tau) \\
\cos \beta(\tau) \cos \gamma(\tau) \\
\sin \beta(\tau)
\end{array}\right) d \tau
$$

The earth frame coordinate system is here assumed to be (east, north, up), the pitch $\beta(t)$ is positive up, and the heading $\gamma(t)$ is magnetic (relative) north.

Here, we start by considering only the data from the DTAG, that is, we have a detailed description of the orientation of the animal but no reliable speed information, and assume therefore as first approximation some (mean) speed $v(t)=v=$ const. The track generated by this assumption of constant speed is called a pseudotrack. The mean speed can be independently estimated using time and GPS position where the tagging occurred and a sighting toward the end of the tag attachment. 
To estimate the final animal track, the DTAG data were combined with the passive sonar data. For this the range and bearing components of the constant-speed pseudotrack $\left(r_{p}\right.$ and $b_{p}$ ) were adjusted to approximate the measured acoustic range and bearing $\left(r_{a}\right.$ and $\left.b_{a}\right)$ to obtain final range and bearing estimates $\left(r_{e}\right.$ and $\left.b_{e}\right)$

$$
\begin{aligned}
& r_{e}(t)=r_{p}(t)+F_{\mathrm{LP}}\left(r_{a}(t)-r_{p}(t)\right), \\
& b_{e}(t)=b_{p}(t)+F_{\mathrm{LP}}\left(b_{a}(t)-b_{p}(t)\right) .
\end{aligned}
$$

The purpose of the low-pass filter $F_{\mathrm{LP}}$ was to avoid impulsive (high-frequency) correction to the constant-speed (zero acceleration) pseudotrack, and therefore to obtain smooth variation in the resulting acceleration of the animal.

\section{Passive sonar}

The passive sonar data were used to estimate the location of the whale while it was clicking during the dive, to correct the speed estimation of the tagged animal, and to characterize the sperm whale clicks. The array was deployed from NRV ALLIANCE and all available nonacoustic data, e.g., GPS position and array depth, were recorded together with the acoustic data.

\section{Array position, depth, and heading}

While the ship position was measured using GPS, the array position had to be estimated by the following method. The array is towed behind the ship with a constant tow cable length. The depth of the array varies as a function of the tow-ship speed. Maneuvers were generally made smoothly to avoid excessive bending in the array. One may therefore assume that the array follows the ship track delayed by a certain time offset, that is, the array position is estimated as the ship's position at a later time

$$
P_{\text {array }}(t+\tau(t))=P_{\text {ship }}(t) .
$$

To obtain the time offset when the array was found at a given position, the ship's mean speed $V_{m}$ is incorporated

$$
\tau(t)=\frac{C_{0}+\sqrt{C^{2}-h(t)^{2}}}{V_{m}(t)}
$$

where $C_{0}$ is the horizontal distance from GPS receiver to stern of NRV ALLIANCE; $C$ is the length of the tow cable; and $h(t)$ is the array depth.

The array depth was measured with a pressure sensor in the array and, as a heading sensor was not available, the array heading was derived directly from the array motion.

\section{Acoustic bearing}

To obtain the acoustic bearing of the sperm whale the time delay between two distant hydrophones of the same click was measured using cross correlation and transformed to angle. The passive sonar (beamformer)-based bearing estimate was not used for this task because, due to the limited number of beams, the existing angular accuracy was not sufficient. However, the clicks were tracked minute by minute on the passive sonar display to cross check the bearing derived from the time delay estimation.

\section{Acoustic ranging}

The range estimation is based on the travel time required for the sperm whale clicks to reach the passive sonar system. Independent range estimation was further carried out by exploiting the multipath structure of the received clicks and used to synchronize the acquisition systems of the DTAG and the passive sonar system.

a. Multipath ranging. The multipath ranging uses the path difference between the sperm whale click and the surface-reflected echo of the same click to estimate the range from the passive sonar to the clicking animal. As we have measured the animal depth by the DTAG, and as we know the array depth of the towed array, multipath ranging only requires the path difference between direct and surfacereflected arrival (Zimmer et al., 2003). Depending upon the geometry, the expected delay between these two arrivals is less than a second. The travel time difference (surface reflected-direct click) was obtained from the automatic click detector applied to the hydrophone data. The surface reflection from some clicks interfered with the direct arrival; these were eliminated from the analysis. Before running the automatic click detector, the hydrophone data were bandlimited to 0.3 to $15 \mathrm{kHz}$ (using a 128-taps FIR filter) to reduce the influence of ambient noise at low frequencies.

b. Click travel time ranging. To estimate the range using the click travel time, the actual time difference of the clicks between passive sonar $\left(t_{S}\right)$ and DTAG $\left(t_{T}\right)$ is measured and multiplied with sound speed $c$, which for small time differences and similar ranges may be assumed to be constant

$$
r=c\left(t_{S}-t_{T}\right) .
$$

However, in order for this method to be successful the data must be sampled synchronously on both systems. As the sampling rate on the tag varies with the temperature of the oscillator crystal, the tag sampling rate is expected to vary as the animal dives deep into regions of colder water. To compensate for this temperature-dependent drift, the click travel time ranging was compared with the data from the multipath ranging and the difference in range estimation was fitted to a temperature-dependent model

$$
\Delta R=c_{0}+c_{1} t+c_{2} t(T-20)^{2} .
$$

Solving this equation for $c_{0}, c_{1}$, and $c_{2}$ for all range differences $\Delta R$ and temperatures $T$ gave an optimal correction to the click travel time range estimation.

c. Hydrophone data processing. We did not use the beamformed data to estimate the spectra and levels of clicks, but used the data directly recorded from individual hydrophones. The time-delay beamforming process uses low-pass filters (8-taps FIR) for interpolation, and a detailed spectral analysis may experience some difficulties due to varying filter characteristics. Also, due to spatial aliasing frequencies above $8.3 \mathrm{kHz}$ may be contaminated by sounds from other directions. The individual hydrophones, on the other hand, are calibrated and have a flat frequency response over the band of interest. The lack of array gain limits the detection capabilities, but this was not considered a major problem for 
this paper. Hydrophones also lack the angular resolution of the beamformer and are susceptible to more interference from shipping noise and conspecifics.

The method for relating orientation of the tagged whale at the time a click was produced to the level received at the hydrophone required matching clicks from the tag and array. The range between the whale and the array was often great enough that once the whale made one click, it might have made several more clicks before the first click was received at the array. However, the varying sequence of ICI makes it possible to uniquely associate each click recorded on the tag with the same click recorded on the array. The two data sets were matched by generating a waterfall sonar plot of the hydrophone data, in which the start of each trace was triggered using the click times as measured on the tag but shifted by a constant time increment to reduce the effect of travel time. This was analyzed on a dive-by-dive basis, with the time increment selected to correspond to the average range during the dive. Due to varying ranges during each dive, the resulting (hydrophone) clicks were not exactly aligned at the same offset time throughout the dive. In a second step, an automatic click detector similar to the one that extracted the clicks from the tag data was used to estimate the correct click travel time difference. The performance of the click detector could be checked graphically to test whether the clicks on the hydrophone waterfall sonar plot lined up at the same time.

To describe the signal strength, the received peak pressure was estimated for each click by taking the maximum value of the signal envelope. For this, the real-valued signal was first Hilbert transformed to obtain an analytic representation after which the magnitude was estimated as the absolute value of the analytic signal (Randall, 1987). An apparent source level (ASL) was obtained by correcting the received pressure level with the transmission loss for the estimated range between whale and hydrophone, for which we assumed spherical spreading. The maximum ASL of a source defines the axis of the sound beam (acoustic axis) and the ASL in that case gives the source level (SL). Off the acoustic axis the ASL is reduced and its beam pattern characterizes sound emission from the source.

\section{RESULTS}

The DTAG was attached for nearly $7 \mathrm{~h}$ to a whale (SW01_275b) estimated by visual observation (Miller et al., 2004) to be about $12.2 \mathrm{~m}$ long. While tagged, the whale performed eight complete deep dives to foraging depths of 550-900 m (Fig. 2). As the water depth for all dives in this Ligurian Sea site was over $2600 \mathrm{~m}$, the dive pattern indicates that the tagged whale was feeding on a midwater prey layer between 550 and $900 \mathrm{~m}$. While the whale transited from surface to foraging depth and from foraging depth to surface without major points of inflection in the vertical axis, during the bottom portion of its dive, it regularly moved up and down through $200 \mathrm{~m}$ of vertical excursion, suggesting that it was exploiting a prey layer about $200 \mathrm{~m}$ thick. The whale started to emit regular clicks during descent soon after fluke-up and continued while at foraging depth. While the tagged whale dove, the surface echo of each click was regu-

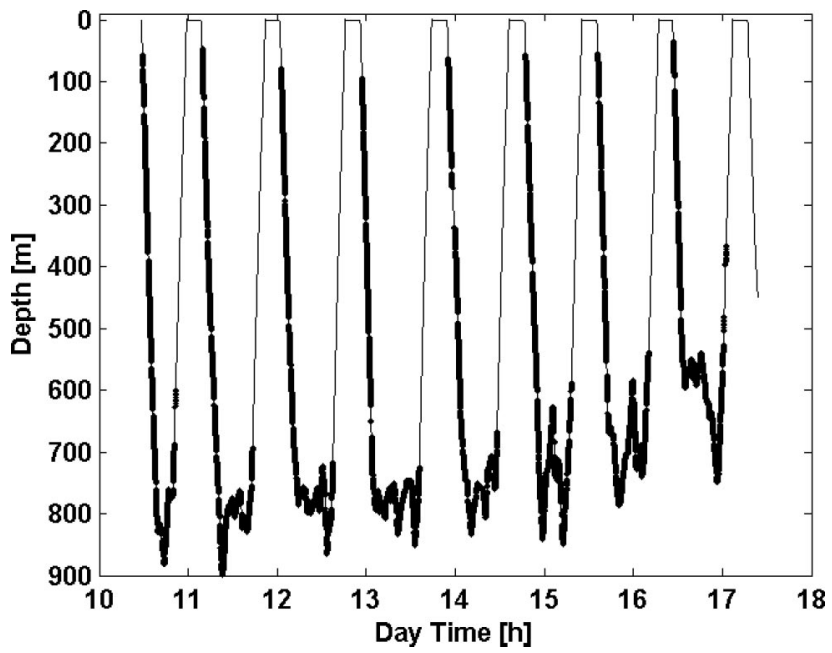

FIG. 2. Depth profile of tagged sperm whale. The whale made eight full dives to depths ranging from 550-900 m. The dots overlaid on the profile indicate the times of click emissions by the whale.

larly recorded on the tag independent of pitch angle. Figure 3 shows a waterfall sonar plot of the first 350 clicks of a dive. The surface echoes are not clipped and are very sharp at onset. On ascent no acoustic activity was observed, apart from a total of 18 codas at end of dives 1 and 8 . The whale only emitted creaks at depths greater than $550 \mathrm{~m}$.

While the whale was tagged, it moved with a mean horizontal speed of $1.22 \mathrm{~m} / \mathrm{s}$ in north-north-westerly direction. Figure 4 shows the reconstructed track of the whale with color-coded depth profile. The track of NRV ALLIANCE shows that the passive sonar system circled the tagged whale four times at ranges from about 0.7 to $6 \mathrm{~km}$. Due to this circling and the varying pitch of the whale, it was possible to record the whale clicks from nearly all aspects.

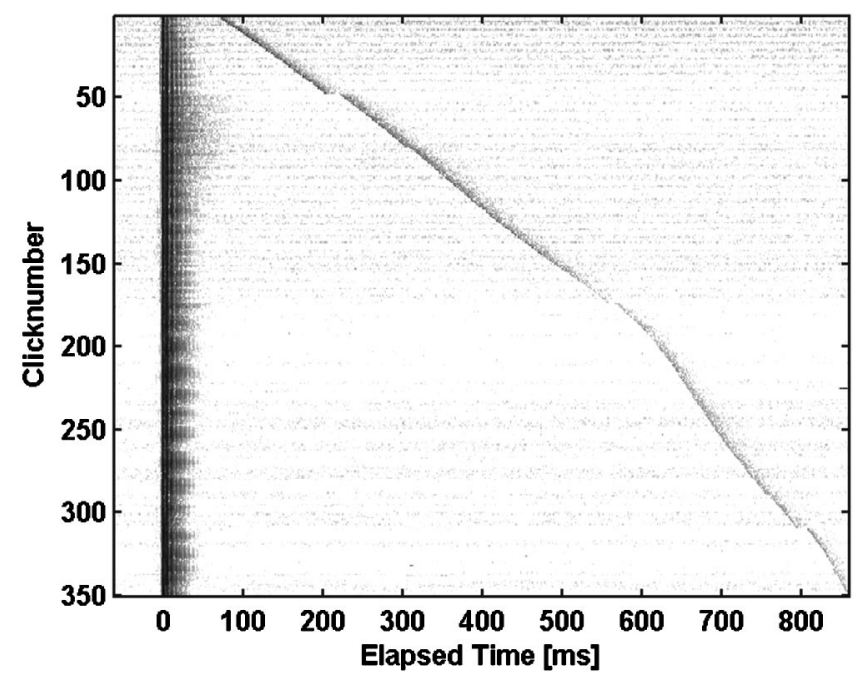

FIG. 3. Waterfall sonar plot of sperm whale clicks recorded from the tag on the whale during descent. Successive clicks are aligned on the left at time $=0$. Surface echoes of the emitted clicks are clearly visible (line with elapsed time increasing to $860 \mathrm{~ms}$ at the bottom of the figure). The corresponding depth values are $52 \mathrm{~m}$ for the first click and $645 \mathrm{~m}$ the 350 th click. The depth of the ocean bottom during this dive was over $2600 \mathrm{~m}$ and echoes from the ocean bottom are not visible. The small discontinuities visible along the surface echo are due to short pauses within the sequence of regular clicks. 


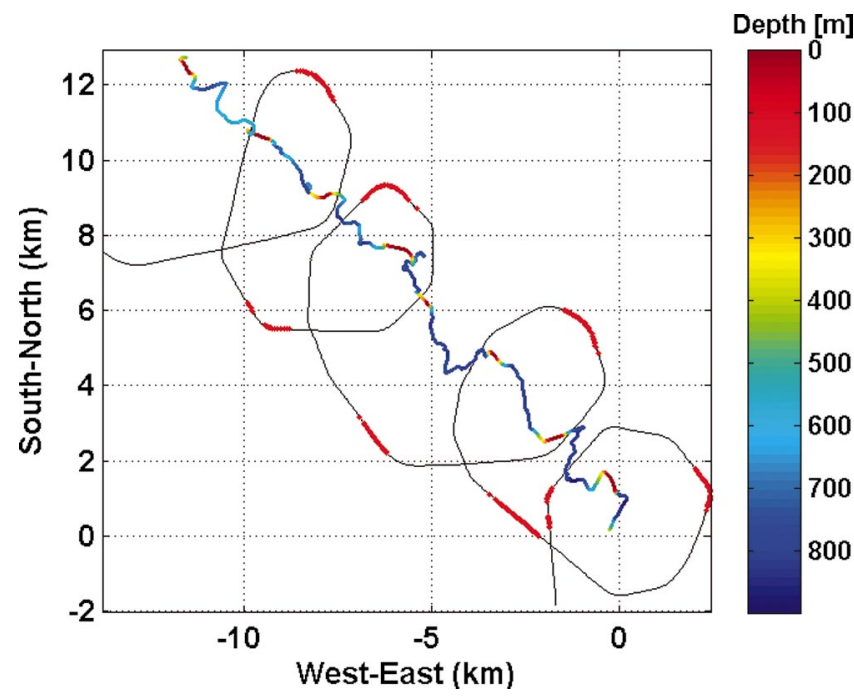

FIG. 4. Reconstruction of the track of the sperm whale tagged in the Ligurian Sea. The track of NRV ALLIANCE is shown in black. The red dots on the ship's track indicate where the visual team sighted the tagged sperm whale. The color-coded line is the track of the animal, where the color map ranges from red for surfacing to blue for a depth of $900 \mathrm{~m}$.

The tag recorded a total of over 36000 regular and creak clicks. Figure 5 shows the histogram of the ICI of all clicks. The data are plotted on a $\log -\log$ scale and show a threemode structure. One mode peaks at ICI of around $1 \mathrm{~s}$ and can be attributed to regular clicks. A weaker mode shows a peak around an ICI of $0.25 \mathrm{~s}$ and the third mode peaks at an ICI of $0.03 \mathrm{~s}$. For the analysis of this paper we selected only regular clicks with ICI above $0.45 \mathrm{~s}$ (vertical dashed line in Fig. 5) and ignored all clicks with ICI below 0.45 that we associated with creaks (Gordon, 1987). According to this threshold, the whale emitted over 14100 regular clicks during the tag attachment. For this paper, we only used regular clicks where the surface reflection could be distinguished from the direct arrival, reducing the number of clicks to just below 13000.

The knowledge of the three-dimensional orientation of the whale at each click allowed the transformation of the

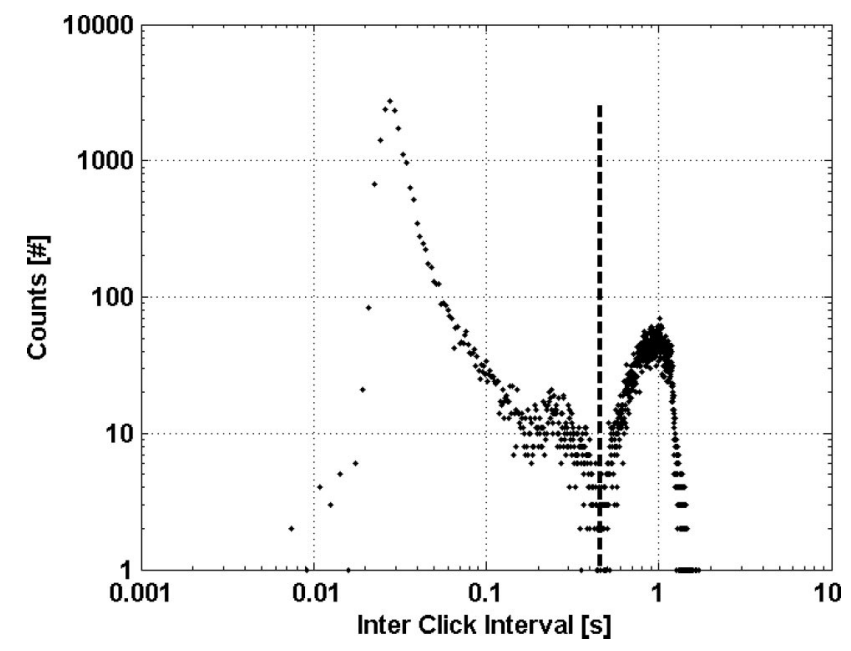

FIG. 5. Log-log plot of distribution of interclick-intervals (ICI) from the tagged whale using all detected clicks $(n>36000)$. The peak centered on $0.025 \mathrm{~s}$ marks the dominant ICI for creak clicks. The peak centered on $1 \mathrm{~s}$ marks the dominant ICI for regular clicks. The vertical dashed line at $0.45 \mathrm{~s}$ marks the lower limit of ICI we used in this paper to define regular clicks.
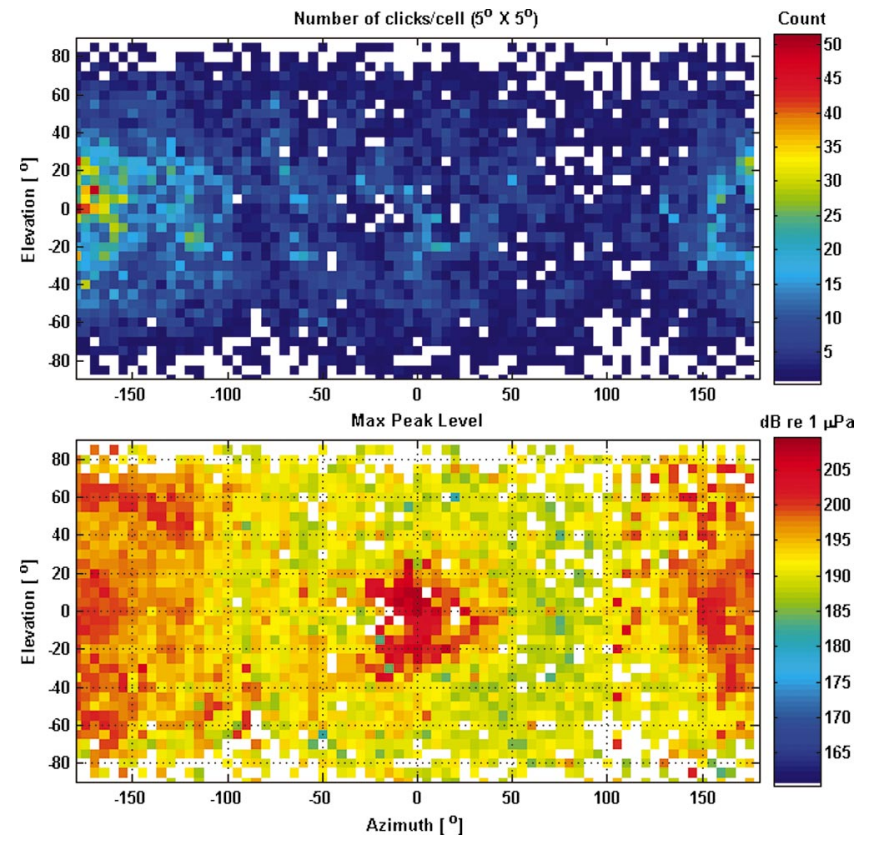

FIG. 6. Aspect coverage and estimated transmit beam pattern of the tagged sperm whale. The pattern is shown as seen from the animal's perspective. The top panel shows the number of clicks falling into each $5^{\circ} \times 5^{\circ}$ cell. The lower panel shows the maximum apparent source level within each cell. The $3 \mathrm{D}$ beam pattern shows two distinct features: a confined concentration of intense clicks in forward directions (around $0^{\circ}$ azimuth and $0^{\circ}$ elevation) and a more diffuse concentration in backward direction $\left( \pm 180^{\circ}\right.$ azimuth and $0^{\circ}$ elevation). The observed levels reach about $210 \mathrm{~dB}_{\text {peak }}$ re: $1 \mu \mathrm{Pa}$ at $1 \mathrm{~m}$ in forward direction and $200 \mathrm{~dB}_{\text {peak }}$ re: $1 \mu \mathrm{Pa}$ at $1 \mathrm{~m}$ in backward direction

coordinates relative to the hydrophone receiver into a whaleframe coordinate system, which made it possible to estimate the azimuth and elevation angles of the whale sound source as seen from the passive sonar. While at depth, the whale rolled and changed pitch from $-90^{\circ}$ to $+90^{\circ}$, so a circling passive sonar could record sperm whale clicks from nearly all vertical and horizontal angles. Using the apparent source levels of nearly 13000 detected regular clicks, we constructed a map of the emitted three-dimensional sound field, or beam pattern of regular sperm whale clicks (Fig. 6).

To obtain this three-dimensional beam pattern, the azimuth and elevation values of all regular clicks were allocated into $5^{\circ}$ by $5^{\circ}$ cells. The cell size resulted as compromise between expected resolution and the number of obtained histogram samples. The top panel of Fig. 6 shows the coverage of the beam pattern in azimuth and elevation with colorcoded counts for the $5^{\circ}$ by $5^{\circ}$ cells. The center of this plot indicates an azimuth and elevation of $0^{\circ}$. This corresponds to the direction directly in front of the whale. This plot uses a coordinate system as seen by the whale. The point with $0^{\circ}$ azimuth and $0^{\circ}$ elevation points directly ahead of the whale. Negative azimuth values indicate angles to the left of the whale, positive azimuth to the right. Similarly positive elevation indicates angles above the horizontal, while negative angles are downwards. A zero count (white) means that no click was measured in the cell with corresponding azimuth and elevation. Azimuth and elevation angles of the beam pattern were estimated assuming constant sound speed between whale and array. The impact of ray refraction due to 

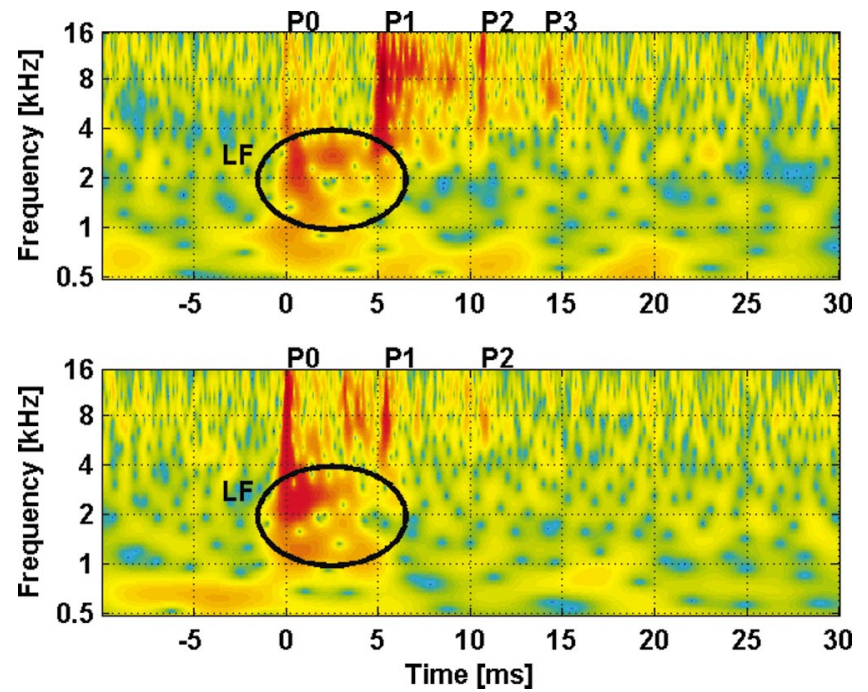

FIG. 7. Wavelet-type spectra (based on Gabor kernel) of forward click (top panel) and backward click (bottom panel) as received by a towed hydrophone. The forward click corresponds to $9^{\circ}$ azimuth and $7^{\circ}$ elevation in the beam pattern, and the backward click to $-137^{\circ}$ azimuth and $-60^{\circ}$ elevation. The individual pulses within each click are labeled P0, P1, P2, and P3, consecutively. The ellipse indicates the low-frequency (LF) component of the click.

depth-dependent variation of the sound-speed velocity (Urick, 1983) varies as a function of range $\left(\sim-3^{\circ}\right.$ at $\left.4 \mathrm{~km}\right)$ and must be considered only at larger ranges $(>6 \mathrm{~km})$ and for increased demands on angular accuracy.

The lower panel of Fig. 6 shows the broadband beam pattern of the regular sperm whale clicks, including frequencies from 300-15000 Hz. To obtain this pattern, the maximum apparent source level (ASL) within each cell was plotted. This approach was necessary because not all of the variations in ASL are due to the click beam pattern, but may also result from variations in click source level (Madsen et al., 2002). By taking the maximum ASL within each cell, a beam pattern is obtained that approximates the maximum level in each direction. This should correspond to the true beam pattern when a sufficient number of clicks are sampled within each cell.

The three-dimensional beam pattern shows two distinct features: a confined concentration of intense clicks in forward direction (around $0^{\circ}$ azimuth and $0^{\circ}$ elevation) and a more diffuse concentration in backward direction $\left( \pm 180^{\circ}\right.$ azimuth and $0^{\circ}$ elevation). The observed levels reach about $210 \mathrm{~dB}_{\text {peak }} r e: 1 \mu \mathrm{Pa}$ at $1 \mathrm{~m}$ in forward direction and $200 \mathrm{~dB}_{\text {peak }} r e: 1 \mu \mathrm{Pa}$ at $1 \mathrm{~m}$ in backward direction.

To further understand this bimodal beam pattern, two representative clicks were selected for detailed analysis, one produced when the ship was in front of the whale and the other from when the ship was behind. These two clicks are from the same dive and separated by $3 \mathrm{~min}$. They are consequently from about the same range. Figure 7 shows wavelet spectra (using a Gabor kernel) (Zimmer et al., 2003) of this forward and backward click. The forward click (top panel) was emitted at $10^{\circ}$ azimuth, $7^{\circ}$ elevation and is characterized by a weak, 4-ms-long component ( 0 to $4 \mathrm{~ms}$ ) at frequencies around $2.5 \mathrm{kHz}$, a very weak short pulse, called $\mathrm{P} 0$, with frequencies above $3 \mathrm{kHz}$ at $0 \mathrm{~ms}$, a strong pulse, called $\mathrm{P} 1$, with frequencies above $3 \mathrm{kHz}$ at $5.3 \mathrm{~ms}$, followed by a weaker pulse, P2 at $10.6 \mathrm{~ms}$, and an again weaker pulse, P3 at $14 \mathrm{~ms}$. The backward click (lower panel) was emitted at $-137^{\circ}$ azimuth, $-60^{\circ}$ elevation, and shows the same low frequency (LF) component ( 0 to $4 \mathrm{~ms}$ around $2.5 \mathrm{kHz}$ ) as seen in the forward click. But, the high-frequency part is different. The short $\mathrm{P} 0$ pulse at $0 \mathrm{~ms}$ is now the strongest pulse, followed by a weaker P1 pulse around $5.3 \mathrm{~ms}$ and a very weak P2 pulse at about $10.6 \mathrm{~ms}$. Both clicks are characterized by an IPI of $5.3 \mathrm{~ms}$, which corresponds to a whale of just over $12.5 \mathrm{~m}$ : $12.53 \mathrm{~m}$ using the formula of Gordon (1991): $L=4.833+1.453(\mathrm{IPI})-(\mathrm{IPI} / 1000)^{2}$, and $12.57 \mathrm{~m}$ using the formula of Rhinelander and Dawson (2004): $L$ $=17.12-2.189($ IPI $)+0.251(\text { IPI })^{2}$. This is a close match to the $12.2 \mathrm{~m}$ estimated visually. In both clicks, the pulse structure occurs only at higher frequencies and there is significant reverberation following the strongest pulse. The LF component of the clicks starts with the first pulse P0 and its duration remains shorter than the IPI. No pulse-like repetition of the low-frequency component is observed.

Figure 7 shows that the individual clicks are too complex to support a single beam pattern. There are at least three different characteristic features: a low-frequency (LF) component common to both the forward- and backward-directed parts of the click, the forward-directed portion dominated by $\mathrm{P} 1$, and the backward-directed part dominated by $\mathrm{P} 0$. We therefore reprocessed the data with narrower time and spectral windows to separate the beam patterns of the LF component, the $\mathrm{P} 0$ and the $\mathrm{P} 1$ pulses. For the following analysis the window definitions were as follows: The LF component was estimated with a spectral window from $300 \mathrm{~Hz}$ to $3 \mathrm{kHz}$ and a time window from -2 to $10 \mathrm{~ms}$. The $\mathrm{P} 0$ component was defined to fall within 3 and $15 \mathrm{kHz}$ and between -2 and $3 \mathrm{~ms}$. The P1 component was defined to fall again within 3 and $15 \mathrm{kHz}$ but between 3 and $8 \mathrm{~ms}$.

Figure 8 shows peak-level beam pattern of the LF component, the P0 and P1 pulses. The figures confirm a nearly omnidirectional LF component with maximum levels ranging from $\sim 170-190 \mathrm{~dB}_{\text {peak }} r e: 1 \mu \mathrm{Pa}$ at $1 \mathrm{~m}$, the $\mathrm{P} 0$ beam pattern pointing backwards with low directionality at maximum levels of $\sim 200 \mathrm{~dB}_{\text {peak }}$ re: $1 \mu \mathrm{Pa}$ at $1 \mathrm{~m}$ and the P1 component pointing forward with high directionality and a maximum measured level of $210 \mathrm{~dB}_{\text {peak }} r e: 1 \mu \mathrm{Pa}$ at $1 \mathrm{~m}$.

To simplify the graphic representation of the beam pattern and to get a better feeling for the directionality, we observe that all three beam patterns exhibit rotational symmetry. It therefore makes sense to plot the peak level estimated as function of the off-axis angle, which is the angle between the forward direction of the acoustic axis and any other combination of azimuth and elevation.

Figure 9 shows the peak level as function of off-axis angle for the three components of a sperm whale click (LF component: top panel; P0 pulse middle panel, P1 pulse bottom panel). All panels show in gray all of the peak-level measurements and in black the 90th percentile of the measurements for a given off-axis angle. Again, we observe that the LF component is nearly independent of the off-axis angle; the P0 pulse increases slowly with the off-axis angle and reaches a maximum close to $180^{\circ}$. The P1 pulse de- 

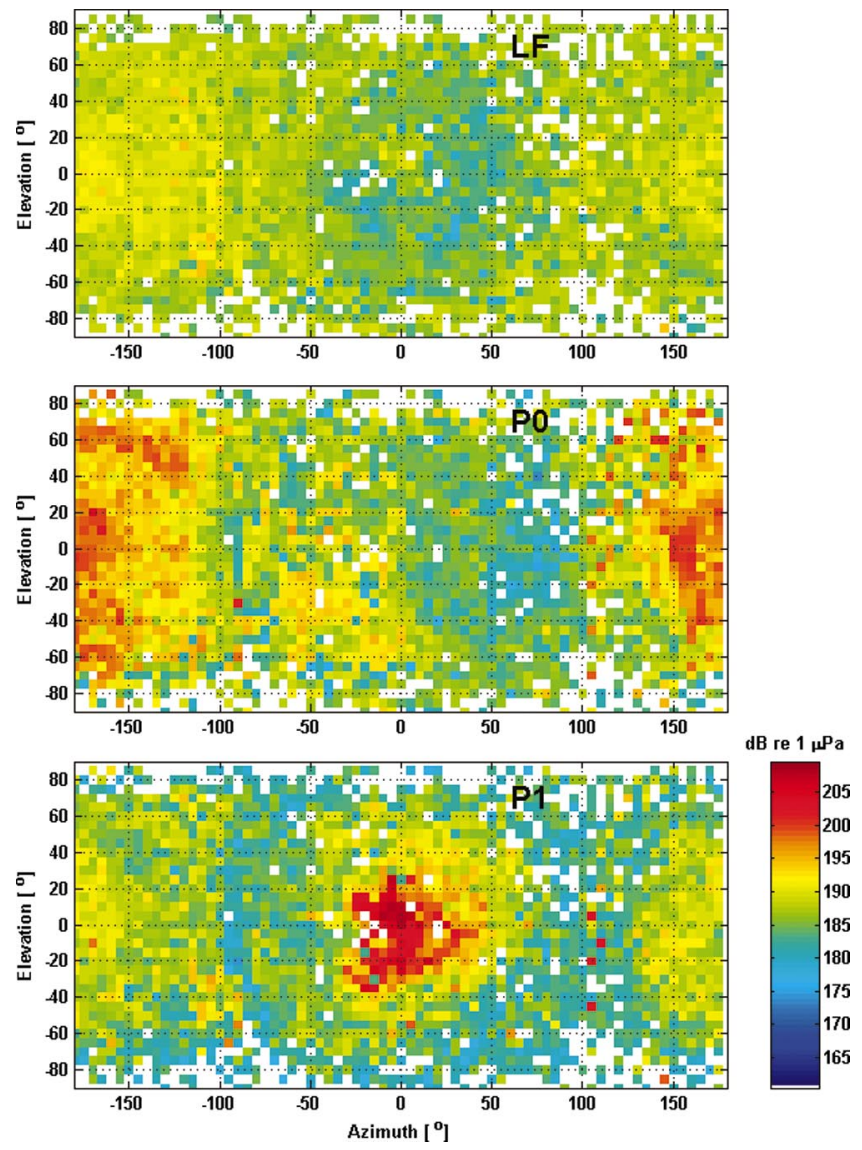

FIG. 8. Map of transmit beam pattern of three components of clicks recorded from the tagged sperm whale. The pattern is shown as seen from the animal's perspective. Each pixel indicates the maximum apparent source level (ASL) recorded within each cell. The LF component is nearly omnidirectional, with click ASLs ranging from $170-190 \mathrm{~dB}_{\text {peak }} r e: 1 \mu \mathrm{Pa}$ at $1 \mathrm{~m}$. The P0 component has a broad beam directed backward (near $\pm 180^{\circ}$, with ASLs in the beam of about $200 \mathrm{~dB}_{\text {peak }} r e: 1 \mu \mathrm{Pa}$ at $1 \mathrm{~m}$. The P1 beam has maximum ASLs near $210 \mathrm{~dB}_{\text {peak }}$ re: $1 \mu \mathrm{Pa}$ at $1 \mathrm{~m}$.

creases with the off-axis angle and remains constant beyond $90^{\circ}$. The standard deviation of peak level was found to be nearly constant at $3.5 \mathrm{~dB}$ as a function of off-axis angle for all three components.

The red curve in the lower panel was modeled as broadband beam pattern for the P1 pulse and is based on a short, Gaussian-shaped pulse emitted from circular piston ( $\mathrm{Au}$, 1993 ) and fitted to the 90th percentile for angles $>20^{\circ}$. The obtained modeled source parameters for the P1 pulse were center frequency $13 \mathrm{kHz}$, signal duration $0.21 \mathrm{~ms}$, piston radius $0.55 \mathrm{~m}$, and maximum source level $229 \mathrm{~dB}_{\text {peak }}$ re: 1 $\mu \mathrm{Pa}$ at $1 \mathrm{~m}$. Replacing the 90th percentile values for angles $<90^{\circ}$ with the modeled beam pattern, the broadband directivity index for the $\mathrm{P} 1$ pulse became $26.7 \mathrm{~dB}$, which is close to the $27 \mathrm{~dB}$ given by Møhl et al. (2003). For comparison, the measured broadband directivity index (based on the 90th percentile) of the backward beam ( $\mathrm{P} 0$ ) is $7.4 \mathrm{~dB}$.

To investigate the origin of the LF component, the peak frequency of the LF spectrum of each pulse was extracted. If the LF component were based on air resonance, then one would expect that the peak frequency would vary as a function of dive depth due to the compression of available air volume. Under certain assumptions (wavelength larger than
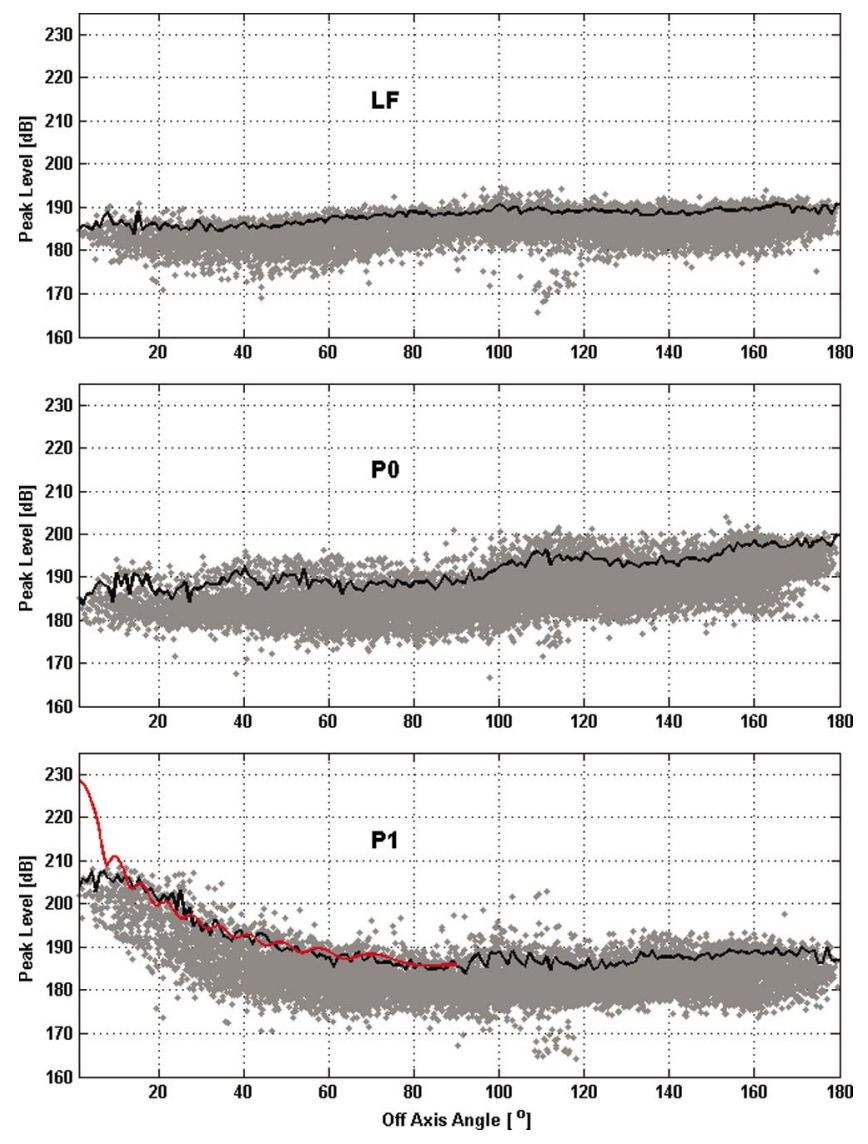

FIG. 9. Beam patterns of click components as a function of off-axis angle. The gray dots are a scatter plot of each measured value. The black line represents the 90th percentile of level for each off-axis angle. For P1, the red line indicates the beam pattern predicted for a circular piston source with the parameters indicated in the text, and is fitted to off-axis angles $>20^{\circ}$ with a maximum on-axis click source level of $229 \mathrm{~dB}_{\text {peak }} r e: 1 \mu \mathrm{Pa}$ at $1 \mathrm{~m}$. Clicks with off-axis angles $<20^{\circ}$ were not used in this fit and the resulting differences are discussed in the text.

the linear dimension of the air volume, speed of sound nearly constant) theory predicts that the resonance frequency should vary with the square root of the static pressure (Kinsler et al., 1982; Medwin and Clay, 1998). Figure 10 shows a scatter plot where the dominant peak frequency in the LF component is plotted against the square root of the static pressure. For pressures up to $53 \mathrm{~atm}$ (vertical dashed line; equivalent to $520 \mathrm{~m}$ ) one can observe two modes for which the peak frequency varies linearly with square root of pressure. For pressures greater $53 \mathrm{~atm}$, or higher depth values, this relationship breaks down. The two black lines correspond to the modeled depth dependence of an air resonator $\left(f_{1,0}\right.$ $=150 \mathrm{~Hz}$ and $d f_{1} / d \sqrt{p}=160 \mathrm{~Hz} / \sqrt{\mathrm{atm}}$ for the lower line and $f_{2,0}=50 \mathrm{~Hz}$ and $d f_{2} / d \sqrt{p}=260 \mathrm{~Hz} / \sqrt{\mathrm{atm}}$ for the steeper line).

Figure 10 was generated by plotting a single peak LF frequency for each click. Consequently, the scatter plot does not reflect completely the presence of the two modes in each click, but only the stronger of the two modes within each click. However, on a statistical basis both modes got a chance to dominate.

The two lines in Fig. 10 cross at surface pressure, indicating a single (or similar) volume at surface with a reso- 


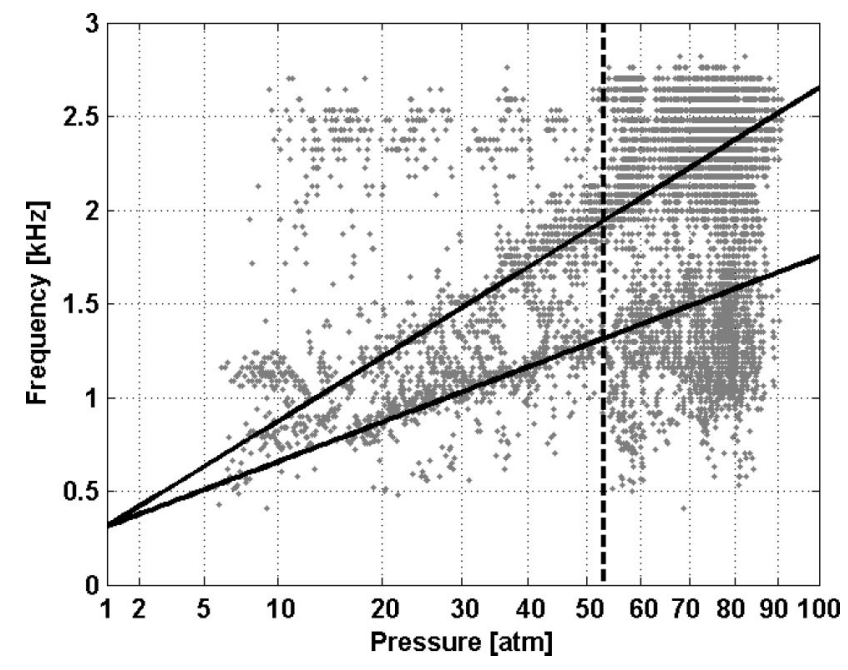

FIG. 10. Variation of the peak frequency of the LF component as a function of pressure. The two solid lines indicate two modes of resonance frequency and indicate that the resonance frequencies vary with the square root of pressure for pressures up to 53 atm (or $520 \mathrm{~m}$; vertical dashed line).

nance frequency of $310 \mathrm{~Hz}$. We do not know the exact mechanism behind this possible air resonance so we only can speculate on the air volume required for this resonance frequency. However, to get a feeling for the dimension of air volume, two models were investigated: free-oscillating air bubbles (Kinsler et al., 1982; Medwin and Clay, 1998) and a Helmholtz resonator (Kinsler et al., 1982). For a freely oscillating bubble, a volume of $4.2 \mathrm{ml}$ is required for a resonance frequency of $310 \mathrm{~Hz}$ at $1 \mathrm{~atm}$. To obtain the volume of a Helmholtz resonator, the dimensions of the neck must be specified. As we only are interested in the order of magnitude, we assume a neck with diameter of $8.6 \mathrm{~cm}$ and an effective length of $2.6 \mathrm{~cm}$. A neck diameter of $8.6 \mathrm{~cm}$ corresponds to the aperture that is consistent with the beam pattern of the $\mathrm{P} 0$ pulse, and the effective neck length of $2.6 \mathrm{~cm}$ is equivalent to the end corrections of a zero-length neck in air. With these assumptions we obtain a resonance air volume of $6400 \mathrm{ml}$.

Even if the estimated volumes are only indicative, they show clearly that the resonance frequency depends on the assumed physical model. An open resonator, like the Helmholtz model, requires a larger air volume than a closed resonator, or air bubble. A more accurate estimate of air volume must use more detailed knowledge of the anatomy of sound production in the sperm whale, especially the location of air during the dive.

\section{DISCUSSION}

Our paper is based on a unique data set from a sperm whale tagged in the Ligurian Sea in 2001. While tagged, the whale emitted over 36600 clicks, of which over 14100 are regular clicks. Nearly 13000 regular clicks were used for estimating the three-dimensional beam pattern. The orientation of the whale was obtained from the accelerometer and magnetometer values from the DTAG. After synchronizing the clocks of the DTAG and the passive sonar towed from the NATO RV ALLIANCE, the click travel time from the whale to the hydrophone array was used to estimate the acoustic range of the whale during its dives. The acoustic bearing was obtained by correlating two hydrophones separated by $10.62 \mathrm{~m}$.

This method, which is totally independent of the technique applied by Møhl and co-workers to discover the high directionality of sperm whale clicks (Møhl et al. 2000, 2003), confirms the basic conclusion that most of the energy of regular clicks is directed forward in a high-powered narrow beam. Møhl et al. (2000, 2003) measured the beam pattern using multiple dispersed receivers to record the same clicks simultaneously. We measured the peak levels of nearly 13000 clicks at varying aspects to a single receiver. Our analysis assumed that the source spectra, and therefore the beam pattern, are similar enough for all of these clicks to allow integration of the measurements into a single beam pattern. The technique used by Møhl et al. (2000, 2003) was unable to define the orientation of the clicking whale with respect to the hydrophones. Our analysis was able to do this, and confirms their conclusion that the main acoustic axis is aligned forward near an azimuth of $0^{\circ}$ and an elevation of $0^{\circ}$ with respect to the whale's body.

Møhl et al. (2003) reported a maximum source level on the axis of the $\mathrm{P} 1$ pulse of up to $235 \mathrm{~dB}_{\mathrm{rms}}$ re: $1 \mu \mathrm{Pa}$ at $1 \mathrm{~m}$. Our data for the $\mathrm{P} 1$ pulse match a modeled beam pattern for off-axis angles $>20^{\circ}$ [Fig. 9(lower panel)] with source levels of $229 \mathrm{~dB}_{\text {peak }}$ re: $1 \mu \mathrm{Pa}$ at $1 \mathrm{~m}$. When comparing our results with the values given by Møhl et al. (2003), one should note that they present the source level as rms value, while we have chosen to use peak values. This allowed us to use data with low signal-to-noise ratio (SNR) for the beam pattern, whereas the rms estimation would have been difficult at low SNR. As rule of thumb, we estimate that, for on-axis sperm whale clicks, rms values would be $5 \mathrm{~dB}$ lower than peak levels of the analytic signal representation of this paper. For off-axis angles $<20^{\circ}$ our measurements only extend up to $210 \mathrm{~dB}_{0-p}$ re: $1 \mu \mathrm{Pa}$ at $1 \mathrm{~m}$, well below the maximum value of the modeled beam pattern and Møhl's results. Part of this discrepancy may stem from Møhl et al.'s (2000, 2003) selection of the few clicks with the highest apparent source levels from weeks of sampling large males in polar waters compared to our analysis of all clicks from a 12-m whale in the Mediterranean. This discrepancy may also stem from three limitations in our data: our limited sampling of on-axis clicks, limitations in the bandwidth of our sampling, and clipping of received levels $>140 \mathrm{~dB}_{\text {peak }}$ re: 1 $\mu \mathrm{Pa}$. The number of points we sampled near the axis of the beam is relatively small: $352<20^{\circ}, 116<10^{\circ}, 37<5^{\circ}$, and $2<2^{\circ}$. The expected number of clicks/degree is $13000 / 180$, or $\sim 70$; the low numbers of clicks sampled on axis probably reflects the tendency for the whale not to pitch upwards while clicking. Given the small sample size, it is very likely that we missed the strongest clicks with off-axis angles less than $2^{\circ}-5^{\circ}$. We also underestimate by some $\mathrm{dB}$ the level of each click due to the limited bandwidth of our data that cover only $\frac{1}{2}$ of the bandwidth of on-axis version of the P1 pulse in sperm whale clicks (Møhl et al., 2000, 2003). Finally the gain settings of the passive sonar system limited the received level to $140 \mathrm{~dB}_{\text {peak }}$ re: $1 \mu \mathrm{Pa}$. To verify how many P1 clicks are clipped, the received level of each click with off-axis 
angle less than $20^{\circ}$ was inspected: 131 of these clicks were recorded within $3 \mathrm{~dB}$ of the clipping level, indicating that for about $1 / 3$ of the near-axis measurements clipping may have occurred.

This paper is the first to use a method capable of separating the $\mathrm{P} 0$ and $\mathrm{P} 1$ pulses based upon orientation of the whale with respect to the receiver. Our data show a difference of $39 \mathrm{~dB}$ between the modeled source level of P1 and the measured ASL of $\mathrm{P} 0$ in forward direction. This difference describes the processing gain of the sperm whale sound production system. Comparing the directivity indices for both the P1 and P0 beam, pattern we obtain a gain of the "bent horn" of about $19 \mathrm{~dB}$ and an effective source level of an initial omnidirectional pulse source of about $210_{\text {peak }} \mathrm{dB}$ re: 1 $\mu \mathrm{Pa}$ at $1 \mathrm{~m}$. The modeled values for the source levels are only indicative and are partially based on extrapolation and rough model assumptions. Nevertheless, these values are consistent with recent results of Møhl et al. (2003).

The dimension of the frontal air sac is about $1 \mathrm{~m}$, corresponding to a good sound reflector for frequencies over 3 $\mathrm{kHz}$ (at $3 \mathrm{kHz}, 2 \lambda \approx 1 \mathrm{~m}$ ). As the spermaceti organ is most likely neither a perfect waveguide nor the frontal air sac a perfect reflector for frequencies below $3 \mathrm{kHz}$, significant lower frequency (LF) sound energy should leave the whale in all directions. Physics can explain why we see an omnidirectional LF frequency component for all sperm whale clicks, but this does not explain how and why this LF frequency component is generated in the first place.

The LF component always immediately follows the P0 pulse and has a long duration, with peak frequencies that are depth dependent down to over $500 \mathrm{~m}$. The lack of repeated pulse structures in the LF component after the P1 pulse indicates that the P1 pulse does not reinforce the resonance as it travels from the frontal sac through the junk. We propose that the initial pulse ( $\mathrm{P} 0)$ generated by the phonic lips activates air volumes connected to the phonic lips, which generates the LF component. The two dominant frequencies in the LF component indicate either one resonator with aspectdependent radiation patterns or that two resonators exist with similar volumes at the surface but different rates at which the volumes are reduced by increasing static pressure. The prediction that resonance frequency should vary with the square root of the static pressure fits well for depths of $<520 \mathrm{~m}$, but not for deeper depths. The reasons for the breakdown of the air resonance model at depth larger than $520 \mathrm{~m}$ are not known.

Our data show that sperm whale clicks are composed of three components with different characteristics: P0, P1, and LF. We suggest that they are all generated by the same acoustic event, the generation of a short pulse at the phonic lips. This pulse excites a low-frequency resonance in adjacent gas cavities that radiates nearly omnidirectionally. The initial pulse itself is mostly directed into the spermaceti organ, but some energy $(<10 \%)$ leaks as broad backward P0 beam. If the source level of the P1 pulse has a source level of 230 $+\mathrm{dB}_{\mathrm{dB}_{\text {peak }}}$ re: $1 \mu \mathrm{Pa}$ at $1 \mathrm{~m}$ as indicated by our model results and as reported by Møhl et al. (2003), and the corresponding P0 pulse has a source level of $200 \mathrm{~dB}_{\text {peak }}$ re: $1 \mu \mathrm{Pa}$ at $1 \mathrm{~m}$, then the $\mathrm{P} 0$ pulse may have $0.1 \%$ of the energy of the
P1 pulse. Most of the energy of the initial backward-directed pulse reflects forward off the frontal sac into the junk and leaves the junk as a narrow, forward-directed P1 pulse. A small fraction of that energy is reflected by the frontal sac back into the spermaceti organ to generate higher-order pulses (Norris and Harvey, 1972; Møhl et al., 2003).

Due to its high directionality, the forward-directed P1 pulse is well suited for echolocation as demonstrated by Møhl and co-workers (Møhl et al., 2003; Møhl, 2001; Madsen, 2002; Madsen et al., 2002). The high source level of the P1 pulse and the long ICI of regular clicks suggest a potential for long detection ranges. Working in areas where the water depth was $<1000 \mathrm{~m}$, Thode et al. (2002) correlated the ICI of sperm whales on the descent phase and the roundtrip travel time to the seafloor, confirming earlier reports that sperm whales may time their clicks to include echoes from the seafloor. On descent, the ICI of sperm whale regular clicks usually have a curious oscillation. Zimmer et al. (2003) demonstrated that this oscillation can correlate with the pitch of a tagged whale. These data stem from a whale tagged in water $2600 \mathrm{~m}$ deep, where the ICI never was long enough to correspond to the round-trip travel time to the seafloor, but does correlate with the depth at which the whale will forage. As the whale changes pitch from straight down to more horizontal, the ICI increases proportional to the slant range of the narrow forward beam to the maximum depth of his foraging dive (Zimmer et al., 2003). This implies that the whale clicks only after the echo from the forward beam returns from the prey layer at which the whale will feed. The correlation of ICI with pitch of the whale would not occur if the whale were listening for echoes from an omnidirectional click. While at depth, sperm whale ICI typically range from $0.5-1.5 \mathrm{~s}$, corresponding to round-trip travel times that are equivalent to maximum sonar ranges of $375-1125 \mathrm{~m}$, assuming that whales do not continue listening for echoes of a previous click once they produce the next one (Au, 1993). It is possible that sperm whales are echolocating for prey at these long detection ranges, but the long ICI may also be used to maintain an overview of the entire auditory scene, similar to bats (Moss and Surlykke, 2001).

While it has not been addressed before, the backwardoriented beam pattern of the $\mathrm{P} 0$ is a necessary consequence of the bent-horn model of sound production for sperm whale clicks, and therefore the beam pattern we have described for the P0 supports the bent-horn model. Considering that the source level of the P0 is 1-3 orders of magnitude weaker than the P1 pulse, one could argue that the existence of the $\mathrm{P} 0$ is only a by-product of the generation of the P1 pulse, and that a backward-oriented beam has no special functionality. On the other hand, the absolute source level of the backward beam is high enough that significant echoes are received on the tagged whale from directions outside of the forward beam. For example, while the whale was descending, the hydrophone on the DTAG usually picked up distinct reflections from the surface (Fig. 3). Echoes from the surface are likely to provide a useful orientation cue, acting like a constant "acoustic horizon," as well as informing the whale of depth, which is important in timing its ascent. Reception of sound from behind requires hearing capabilities in backward 
direction. As a complete three-dimensional receiving beam pattern is not known for sperm whales, one can only speculate that in analogy to dolphins (e.g., Tursiops truncatus; Au, 1993), sperm whales have a frequency-dependent receiving beam pattern with equal or less directionality than the transmit beam pattern. Given the signal-to-noise ratio of surface echoes on the tag, it would be surprising if the whale could not hear the surface echoes of its own click and use that information. The ICI of the regular clicks is frequently long enough to allow reception of surface echoes before the next click is emitted. The whale may time the ICI in order to receive information from all relevant elements of its auditory scene, including surface and bottom.

If our interpretation that the LF component is produced by a resonating gas volume stimulated by the initial pulse is correct, then this supports the hypothesis that the initial pulse energy is generated by a pneumatic mechanism. Thode et al. (2002) reported a shift in frequencies in the $10-15-\mathrm{kHz}$ band of sperm whale clicks as a function of depth, and proposed that this was caused by changing resonant frequencies of reducing air volumes. They suggested that the highfrequency sounds they were analyzing might represent "generator noise," or incidental sounds that are by-products of the sound generation system. Before ruling out any functionality of the LF component, one should note that this lowfrequency component with its low directionality often travels furthest and allows the detection over long distances. The long-range propagation would allow conspecifics to listen over long distances of more than $15 \mathrm{~km}$ to the acoustic activities of sperm whales (Madsen et al., 2002). This LF component is the most likely signal that enables separated sperm whales to synchronize their diving behavior (Whitehead, 1996).

In summary, regular clicks of sperm whales have several components by which the whale simultaneously produces a narrow, high-frequency sonar beam to search for prey, a lessdirectional backward pulse, by-product or not, that provides orientation cues, and a low-frequency component of low directionality that conveys sound to a large part of the surrounding water column with a potential for reception by conspecifics at considerable ranges.

\section{ACKNOWLEDGMENTS}

This work was carried out within the Acoustic Risk Mitigation Program of NATO Undersea Research Center. Thanks to the science party and ship's crew on the research cruise during which these data were collected. The whale was tagged under a scientific research permit No. 9811578-00 issued by the U.S. National Marine Fisheries Service to Peter L. Tyack. This is contribution No. 11019 from the Woods Hole Oceanographic Institution. The Woods Hole Oceanographic Institution Animal Care Use Committee approved this research. This work was funded by grants from the Office of Naval Research Grants N00014-99-1-0819 and N00014-01-1-0705, and the Packard Foundation.

Abraham, D. A. (2000). "Passive Acoustic Detection of Marine Mammals," SM-351 (SACLANT Undersea Research Centre, La Spezia, Italy). $\mathrm{Au}$, W. W. L. (1993). The Sonar of Dolphins (Springer, New York).
Backus, R. H., and Schevill, W. E. (1966). "Physeter Clicks," in Whales, Dolphins and Porpoises, edited by K. S. Norris, (University of California Press, Berkeley), pp. 510-527.

Fristrup, K. M., and Harbison, G. R. (2002). "How do sperm whales catch squids?" Marine Mammal Sci. 18, 42-54.

Gordon, J. C. D. (1987). "Sperm whale groups and social behaviour observed off Sri Lanka," Ph.D. thesis (University of Cambridge, UK).

Gordon, J. C. D. (1991). "Evaluation of a method for determining the length of sperm whales (Physeter catodon) from their vocalizations," J. Zool. 224, 310-314.

Gordon, J., and Tyack, P. L. (2002). "Acoustic techniques for studying cetaceans," in Marine Mammals: Biology and Conservation, edited by P. G. H. Evans and T. Raga (Plenum, London).

Griffin, D. R. (1958). Listening in the Dark (Yale University Press, New Haven).

Jaquet, N., Dawson, S., and Douglas, L. (2001). "Vocal behavior of male sperm whales: Why do they click?" J. Acoust. Soc. Am. 109, 2254-2259.

Johnson, M., and Tyack, P. L. (2003). "A digital acoustic recording tag for measuring the response of wild marine mammals to sound," IEEE J. Ocean. Eng. 28, 3-12.

Kinsler, E., L., Frey, A. R., Coppens, A. B., and Sanders, J. V. (1982). Fundamentals of Acoustics (Wiley, New York).

Kinzey, D., and Gerrodette, T. (2001). "Conversion factors for binocular reticules," Marine Mammal Sci. 17, 353-361.

Madsen, P. T. (2002). "Sperm whale sound production," $\mathrm{PhD}$. dissertation (University of Aarhus).

Madsen, P. T., Wahlberg, M., and Møhl, B. (2002). "Male sperm whale (Physeter macrocephalus) acoustics in a high latitude habitat: Implications for echolocation and communication," Behav. Ecol. Sociobiol. 53, 31-41.

Madsen, P. T., Payne, R., Kristiansen, N. U., Wahlberg, M., Kerr, I., and Møhl, B. (2002). "Sperm whale sound production studied with ultrasound time/depth-recording tags," J. Exp. Biol. 205, 1899-1906.

Madsen, P. T., Carder, D. A., Au, W. W. L., Nachtigall, P. E., Møhl, B., and Ridgway, S. H. (2003). "Sound production in neonate sperm whale," J. Acoust. Soc. Am. 113, 2988-2991.

Medwin, H., and Clay, C. S. (1998). Fundamentals of Acoustic Oceanography (Academic, San Diego).

Miller, P. J. O., Johnson, M. P., Tyack, P. L., and Terray, E. A. (2004). "Swimming gaits, passive drag and buoyancy of diving sperm whales Physeter macrocephalus," J. Exp. Biol. 207, 1953-1967.

Møhl, B. (2001). "Sound transmission in the nose of the sperm whale Physeter catodon. A postmortem study," J. Comp. Physiol., A 187, 335-340.

Møhl, B., and Andersen, S. (1973). "Echolocation: High-frequency component in the click of the harbor porpoise (Phocoena ph. L.)," J. Acoust. Soc. Am. 54, 1368-1372.

Møhl, B., Wahlberg, M., Madsen, P. T., Heerfordt, A., and Lund, A. (2000). "Sperm whale clicks: Directionality and source level revisited," J. Acoust. Soc. Am. 107, 638-648.

Møhl, B., Wahlberg, M, Madsen, P. T., Heerfordt, A., and Lund, A. (2003). "The monopulsed nature of sperm whale clicks," J. Acoust. Soc. Am. 114, $1143-1154$.

Moore, K. E., Watkins, W. A., and Tyack, P. L. (1993). "Pattern similarity in shared codas from sperm whales (Physeter catodon)," Marine Mammal Sci. 9, 1-9.

Moss, C., and Surlykke, A. (2001). "Auditory scene analysis by echolocation in bats," J. Acoust. Soc. Am. 110, 2207-2226.

Mullins, J., Whitehead, H., and Weilgart, L. (1988). "Behaviour and vocalization of two sperm whales, Physeter macrocephalus, off Nova Scotia," Can. J. Fish. Aquat. Sci. 45, 1736-1743.

Norris, K. S., and Harvey, G. W. (1972). "A theory for the function of the spermaceti organ of the sperm whale (Physter catodon L.)," in Animal Orientation and Navigation, edited by S. R. Galler, K. Schmidt-Koenig, G. J. Jacobs, and R. E. Belleville, SP-262 (NASA, Washington D. C.), pp. 397-417.

Page, S. E. (1954). "Continuous inspection schemes," Biometrika 41, 100115.

Randall, R. B. (1987). Frequency Analysis (Brüel \& Kjær, Nærum, Denmark).

Rendell, L. E., and Whitehead, H. (2003). "Vocal clans in sperm whales (Physeter macrocephalus)," Proc. R. Soc. London, Ser. B 270(1512), 225-231.

Rhinelander, M. Q., and Dawson, S. M. (2004). "Measuring sperm whales 
from their clicks: Stability of interpulse intervals and validation that they indicate whale length," J. Acoust. Soc. Am. 115, 1826-1831.

Thode, A., Mellinger, D. K., Stienessen, S., Martinez, A., and Mullin, K. (2002). "Depth dependent acoustic features of diving sperm whales (Physeter macrocephalus) in the Gulf of Mexico," J. Acoust. Soc. Am. 112, $308-321$

Tyack, P. L. (1997). "Studying how cetaceans use sound to explore their environment," Perspec. Ethol. 12, 251-297.

Urick, R. J. (1983). Principles of Underwater Sound (McGraw-Hill, New York).

Wald, A. (1947). Sequential Analysis (Wiley, New York).

Watkins W. (1980). "Acoustics and the behavior of sperm whales," in Animal Sonar Systems, edited by R. Busnel and J. F. Fish (Plenum, New York), pp. 291-297.

Watkins, W. A., and Daher, M. A. (2004). "Variable spectra and nondirectional characteristics of clicks from near-surface sperm whales (Physeter catodon)," in Echolocation in Bats and Dolphins, edited by J. A. Thomas, C. F. Moss, and M. Vater (The Univeristy of Chicago Press, Chicago), pp. $410-413$
Watkins, W. A., and Schevill, W. E. (1977). "Sperm whale codas," J. Acoust. Soc. Am. 62, 1485-1490.

Weilgart, L., and Whitehead, H. (1988). "Distinct vocalizations from mature male sperm whales (Physeter macrocephalus)," Can. J. Zool. 66, 19311939.

Weilgart, L., and Whitehead, H. (1993). "Coda communications by sperm whales (Physeter macrocephalus) off the Galapagos Islands," Can. J. Zool. 71, 744-752.

Whitehead, H., and Weilgart, L. (1991). "Pattern of visually observable behavior and vocalizations in groups of female sperm whales," Behaviour 118, 275-296.

Whitehead, H. (1996). "Babysitting, dive synchrony, and indication of alloparental care in sperm whales," Behav. Ecol. Sociobiol. 38, 237-244.

Zimmer, W. M. X., Johnson, M. P., D'Amico, A., and Tyack, P. L. (2003). "Combining data from a multisensor tag and passive sonar to determine the diving behavior of a sperm whale (Physeter macrocephalus)," IEEE J. Ocean. Eng. 28, 13-28. 